\title{
PREZADOS LEITORES,
}

Eu não poderia deixar passar em brancas nuvens, "O papa é pop" ! O pontífice mais uma vez se identifica não só com o povo, mas também com a comunidade cientifica (algo incomum, levando-se em conta os argumentos de fé e religião!). Leva em conta aspectos, não só de sustentabilidade, ética, além de tecnologias e espiritualidade, assuntos pertinentes aos crentes e não crentes. Uma visão que tornou a encíclica palatável e abrangente. Apresenta uma assertiva ecológica, que chama atenção de que antes de humanos, "Nós somos terra. Todo nosso corpo é constituído de elementos do planeta, seu ar é aquele que nos dá a respiração e sua água vivifica e restaura", e para permanecermos como humanos e atores do espetáculo da vida, "o grito da Terra é o grito dos pobres", temos deveres e responsabilidades para com a Terra e seus inúmeros e diversificados habitantes. Afinal, somos a espécie "que sabe que sabe (Homo sapiens sapiens), ou seria, polui, sabe que polui e não se importa, desde que tenha lucro com isso? Ou pior, que possa responsabilizar outro por isso? Ou ainda, temos tempo para consertar o dano". Somos a espécie que pode modificar, ampliar, reduzir e organizar. Que pode antes de tudo influenciar o comportamento próprio e de outros, através da ferramenta mais poderosa, não porque é visível, estática e de propriedade de alguém, ou que mata e escraviza, mas exatamente por ser incidente, questionadora, penetrante em todas as mentes e libertadora por excelência: A EDUCAÇÃO. Sem ela não temos a sociedade, temos um mero aglomerado de seres que não se entrosam, não se entendem e por isso não formam laços sólidos e solidários, nem entre si, nem com a Terra, onde vivem e retiram o seu sustento. Esperamos mais uma vez que o nosso aglomerado humano perceba e atue de forma não só a preservarmos por mais um período de tempo o nosso amado habitat, mas que, possamos contribuir cada vez mais e melhor para o futuro de outros habitantes, pois não somos eternos, entendemos isso, mas não precisamos ser efêmeros.

Neste número de nossa revista, gostaria de chamar a atenção para algumas modificações que vem de encontro, não só a busca da qualidade editorial, mas também, fazem parte do seu processo evolutivo nestes 3 anos de percurso. A SUSTINERE dá as boas vindas aos novos integrantes do Corpo Editorial, os Professores: MSc. Elizabeth dos Santos Rios (UERJ), DSc Fábio Oliveira Bitencourt Filho, International Federation of Hospital Engineering (IFHE);Universidade Estácio de Sá (UNESA) e Associação Brasileira para o Desenvolvimento do Edificio Hospitalar (ABDEH), DSc Indira Molo-Alvarado, Ministerio de Desarrollo Agropecuario Dirección de Sanidad Vegetal Vigilancia Fitosanitaria, (Panamá) e a DSc Iris Lettiere do Socorro Santos da Silva (UFRA -Universidade Federal Rural da Amazônia). A revista está em franca campanha para inclusão em novas bases de dados, inclusive o DOAJ, que já nos enviou contato e esperamos em breve estar atendendo às solicitações e com isso estarmos aptos a receber avaliação do Qualis Capes. Como já comunicado, a nossa revista obteve o seu ISSN e confirmamos que os números de DOI de cada artigo já se encontram disponíveis, agora no próprio artigo, que também terá uma nova apresentação, fruto do excelente trabalho de nosso querido Editor Gerente, o Bruno Ximenes. 
Esperamos que o número de Dezembro/15, nos traga mais mudanças e qualificação, bem como novos parceiros.

Apresentamos então o conteúdo deste número. Na coluna de Notícias, esperamos que apreciem os resumos e cliquem nos links para maiores informações. A coluna Olhar Profissional traz a visão da Pedagoga Priscila Pinheiro Monzato a respeito da atuação do Pedagogo no espaço de Recursos Humanos. A coluna Nas Prateleiras, apresentamos alguns livros que com certeza serão bem-vindos como fonte de consulta para docentes e discentes, bem como o publico em geral. Na coluna Artigos apresentamos as seguintes contribuições de docentes e discentes que irão fornecer subsídios para leitura informativa e de base científica nas áreas de saúde humana e Ambiental, além de Educação Ambiental: LÚPUS ERITEMATOSO CUTÂNEO: MANIFESTAÇÕES CLÍNICAS E ANÁLISE LABORATORIAL de Priscila Maria da Silva Gomes; POLUIÇÃO AMBIENTAL, UM PROBLEMA DE URBANIZAÇÃO E CRESCIMENTO DESORDENADO DAS CIDADES de Anderson Martins Vianna; INDICADORES DE SUSTENTABILIDADE PARA MONITORAMENTO DE PROJETOS DE RECUPERAÇÃO DE ÁREAS DEGRADADAS de Thaiane Soares Montandon; IMPACTOS AMBIENTAIS HIDROLÓGICOS OCASIONADOS PELO DESFLORESTAMENTO METROPOLITANO: PETRÓPOLIS, RJ de Tamara Magalhães da Silva e ANÁLISE DOS RESÍDUOS SÓLIDOS E ALTERNATIVAS PARA MINIMIZAR SEUS EFEITOS EM UMA UNIDADE DE ENSINO DE JOVENS E ADULTOS DO RIO DE JANEIRO de Antonio Carlos do Prado Ribeiro.

Sem mais, deixamos aos leitores o exemplar da nossa Revista SUSTINERE, que certamente trará uma leitura agradável a todos.

Thereza Camello

Editor Chefe - SUSTINERE 